\title{
The Application of Smart Grid in the Intelligent Agriculture Production
}

\author{
Wenjing Li \\ State Grid Electric Power Research Institute \\ Beijing, China \\ e-mail: liwenjing@sgepri.sgcc.com.cn
}

\author{
Xinling $\mathrm{Wu}$ \\ State Grid Electric Power Research Institute \\ Beijing, China \\ e-mail: xinling-wu@sgepri.sgcc.com.cn
}

\begin{abstract}
This article conducted a preliminary exploration of the smart grid application mode in the rural power grid. The smart management and efficient application of important electricity load during agricultural production process has been realized by disposing energy efficiency management platform in rural areas. Various types of sensors and actuators has been installed in rural production in order to comprehensively monitor the production environment, collect the electricity information of important load and remotely control of the partial ancillary facilities. In the mean time, the information exchanging has been proposed among the energy efficiency management platform, the distributed energy systems, the distribution automation system and the data acquisition system. As a result, the intelligent scheduling of distributed energy can been realized in rural production during the peak period of electricity load and the affluent period. This whole scheme can promote the transformation of the rural electricity structure as well as ensuring stability running of power grid.
\end{abstract}

Keywords-smart grid; power demand-side management; internet of things; cloud computing.

\section{INTRODUCTION}

Rural power grids is one of the key infrastructure in the rural area, which relates to the farmers Living Standards, the level of agricultural production and the rural prosperity. Since 1998, China began to implement the rural electric network modification, electric power management system reform and the policy "equally charged for equal net". Because of these measures, the Rural power grid structure has been obviously improved, the Supply reliability has been enhanced notably, the Electricity prices of Rural residents has Significantly reduced, and has created favorable conditions for economic and social development in rural areas.

With the rapid advance of strong and smart grid construction in China, intelligent rural power grid has played an important role in promoting green development of new countryside, ensuring the safety and reliability of the new rural power grid, enhancing new rural network communication capability, stimulating the development of new agricultural and enriching rural service connotation. For servicing energy conservation, the economic development and the people's livelihood construction, the smart rural power grid has become an important foundation and driving force of new rural model for regional development in China. The application of power grid in Intelligent agriculture production can enhance the overall level of new rural information for three reasons: (1) promote the integration of energy and information in depth as well as ensure the reliable energy supply, (2) promote agricultural production structure upgrading by optimizing the economic structure and proving the technological innovation in related fields, (3) realize the conversion of power enterprises from the single energy suppliers to integrated service providers, which supports for the new rural economic development [1-6].

This article conducted a preliminary exploration of the smart grid application mode in the rural power grid. The smart management and efficient application of important electricity load during agricultural production process has been realized by disposing energy efficiency management platform in rural areas. Various types of sensors and actuators has been installed in rural production in order to comprehensively monitor the production environment, collect the electricity information of important load and remotely control of the partial ancillary facilities. In the mean time, the information exchanging has been proposed among the energy efficiency management platform, the distributed energy systems, the distribution automation system and the data acquisition system. As a result, the intelligent scheduling of distributed energy can been realized in rural production during the peak period of electricity load and the affluent period. This whole scheme can promote the transformation of the rural electricity structure as well as ensuring stability running of power grid.

\section{SYSTEM ARCHITECTURE}

The rural production intelligentization discussed in this paper mainly involved typical agricultural production systems, like greenhouses, warehouses of agricultural equipment and agricultural drip irrigation system. The smart grid architecture used in rural area is shown in Fig. 1.

The whole system can be mainly divided into three layers as following.

(1) Terminal information perception layer. With the quantities of terminals, power meters and actuating equipment, the internet of things has been realized in order to overall percept and intelligently monitor the production information in the rural area.

(2) The communication layer. Considering the distinguishing features of rural production scenes, the new power wireless broadband communication system was proposed. This innovative communication mode used in rural area can solve the problems of geographically dispersion, the wiring difficulties and the long distances among the production places. In addition, this methods can 
realize the coverage of perceived terminal with the highspeed, omnipresent and convenient communication network. The perceptual system can be flexibly expanded.

(3) The demand side management system layer. The numerous information of agricultural production has been collected with the above two layers. The electricity information and environmental messages are comprehensively analyzed through the central cloud processing platform. Along with the exchanging information from the distributed energy access management system, the distribution automation system and the data acquisition system, strategic decision of the energy use in production process can be intelligently made.

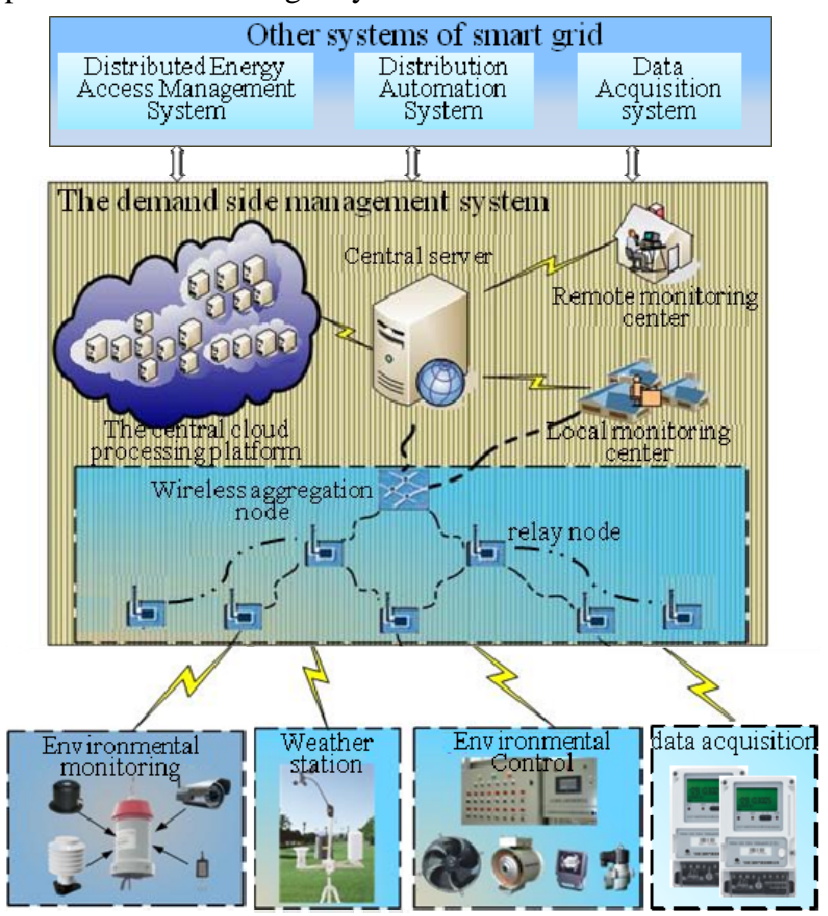

Figure 1. The smart grid architecture used in rural area.

\section{THE PRINCIPLE OF TECHNOLOGY}

\section{A. Terminal information perception layer}

With the application of Internet of Things technology, multi-class sensors, power meters and actuating equipments were deployed in order to percept a variety of information .

The environmental monitoring sensors in greenhouse mainly include soil moisture sensors, soil temperature sensors, air temperature and humidity sensors, light sensors, rain sensors, wind speed and direction sensors, transmitter of oxygen concentrations, carbon dioxide concentration sensors.

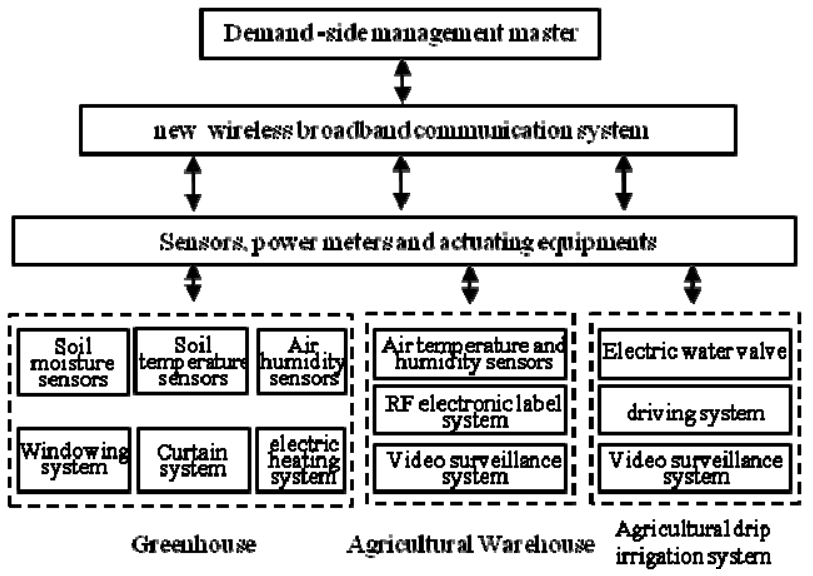

Figure 2. The functional block diagram of the smart grid system

The agricultural warehouse mainly configures the air temperature and humidity sensors and RF electronic label system. Air temperature and humidity sensors are used to detect compartment air temperature and humidity. When air humidity exceeds a certain value, dehumidification equipment will be started to avoid rusting of large equipments caused by Excessive humidity. The RF electronic tagging system is used to detect the situation of entering and exiting warehouse for the agricultural equipments.

The implementing equipments of the intelligent system of agricultural production were primarily installed in the greenhouse and machinery warehouse. The actuating equipments in greenhouse include windowing system, the curtain system, fan-wet curtain cooling systems, electric heating system, irrigation systems and carbon dioxide supply system. The actuating equipments in warehouse include dehumidifier, gate control system and Video surveillance system.

\section{B. The communication layer}

Remote communication adopted new power wireless broadband private network. This new method 4G wireless technologies in $230 \mathrm{MHz}$ frequency. It has several merits compared with traditional $230 \mathrm{MHz}$ system and wired communication schemes, like networking flexibility, larger coverage area and communications capacity.

The wireless broadband communication terminal needs to be installed in the greenhouses, irrigation system and agricultural equipment warehouses. Local communication can adopt RS485 industrial bus or ZigBee wireless LAN depending on site conditions and the type of selected sensor.

The wireless network is designed to provide safe, reliable data transmission channel between the remote monitoring module and the main station. In addition, it can realize the configuration and management for network devices and remote communication modules. The system uses all-IP network construction and the network architecture is shown as Fig. 3. 


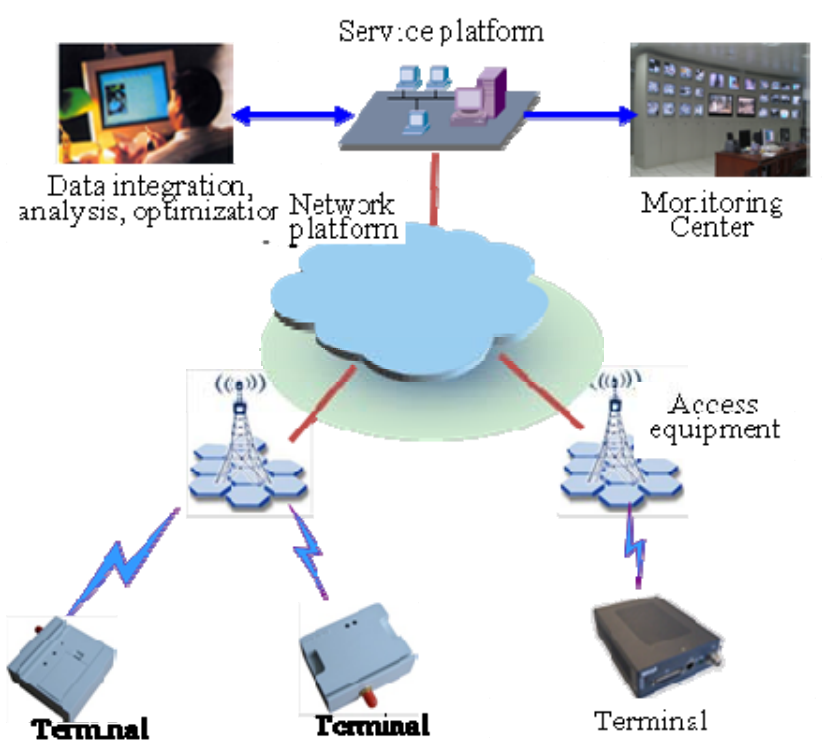

Figure 3. Network architecture of wireless broadband communication system.

Terminal equipments charge the data aggregation and upload. They can also issue the control messages in the downstream. The access equipments are used to realize the wireless coverage and the access controlling of terminal equipment. The network equipments support the data transmission and the control and management of access network. The service platform supports the statistics , query , analysis of information and the access of power service.

The core network equipments can be installed in the same room with the grid master or in the nearby distribution transformer station area connected via optical fiber. The optical fibers are also used to connect the base station and the core network and between the BBU and RRU inside the base station. The communication channel between the terminal and the base station belongs to the TD-LTE wireless network technology.

The sensors and power meters communicate with terminal through RJ45 or RS485. They exchange information via the responding serial protocols. The information of environment and power utilization will be connected to the power wireless broadband communication channel through terminals.

The video surveillance cameras were connected to the communication terminal via the network port. The information were also accessed to the power wireless broadband communication channel through terminals.

Communication terminals installed in the field with $220 \mathrm{~V}$ and adapter power supply. The equipment information upload to the main station via the wireless channels.

\section{The demand side management system layer}

Intelligent demand-side management is one of the most important support parts for smart grid. This system can realize the acquisition, transmission, integration, analysis, optimization and presentation of data. The demand-side resources of distributed generation and the power equipments can be flexible integrated and intelligently dispatched by the advanced information and communication and control technology. The interactions between both sides of supply and demand can be enhanced and the power consumption mode can be guided through demand-side management. In addition, this system can enhance the efficiency of electric power consuming, optimize the allocation of resources, improve and protect the environment, and realize the minimum cost of electricity service at the same time.
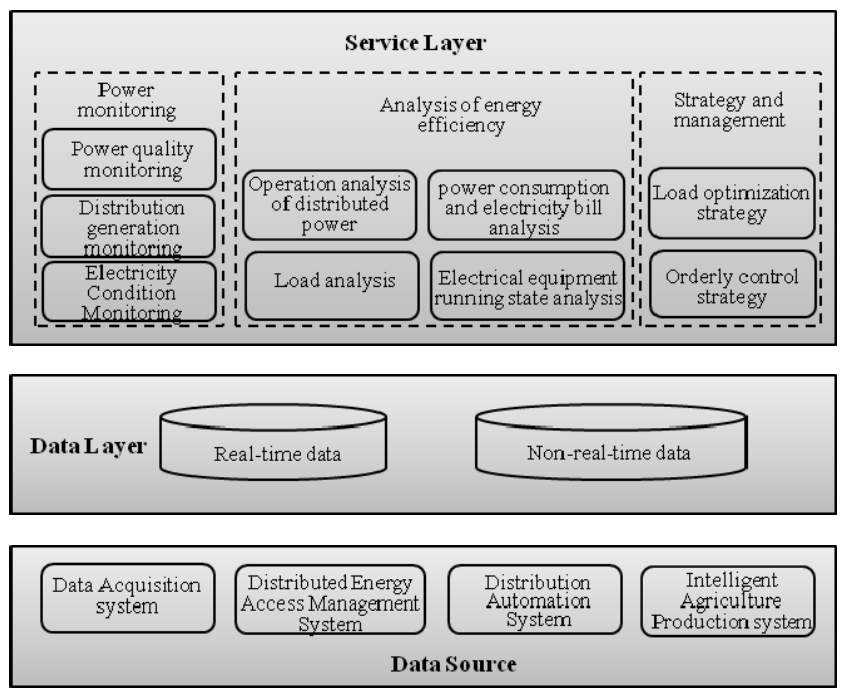

Figure 4. Network architecture of the demand side management system.

The demand-side management system can supervise the production power and distributed generation. Then it can integrate and automatic deploy multi-service systems. After that, this system will proposed load optimization tips in order to coordinate and optimize regional demand-side resources and enhance the whole level of regional energy efficiency.

The demand-side management system dispatched and promoted the local consumption of the clean energy. During the peak period, the power will be supplied by the clean energy instead of commercial power. As a result, the use of clean energy optimizes the grid load curve. In meantime, the requirement of rural production can support the long-term uninterrupted operation of large-scale wind farm wind power generation system, which extends the operational life of the wind turbine.

\section{EXPECTED RESULTS}

With the featured applications of cloud computing and internet of things, the system focused on these following aspects to improve the traditional rural production process.

(1) Agricultural production information has been panoramically collected and intelligently monitored.

Through the information acquisition and data analysis of sprinkler irrigation equipments and the agricultural warehouses, the detailed situation of power utilization was mastered, the model of power utilization was established and the power utilization advising was proposed properly. As a 
result, the method of power utilization was promoted to transform, the proportion of electrical energy in the energy use in the rural production process will be enhanced obviously. As well as improving the energy structure and promote the energy conservation, the power supply can be expanded and the marketing scope can be broadened.

(2) Demand-side intelligent management. Through the deployment of demand-side management system, guide the rural energy structure changing from traditional energy into electrical energy. The local consumptive of Clean energy will be enhanced in greenhouses, the Pumping irrigation system and electric heating. The scale application of clean energy can effectively solve the "Fake electricity shortage" caused by imbalance of supply and demand in spring. In addition, it can settle down the voltage fading problem because of over large power supply radius and improve the power quality.

(3) The explorations for local consumptive mode of distributed energy.

Through demand-side load management and power scheduling, local consumptive mode of distributed energy in the rural area was discussed. The consumption and access method to the power grid of distributed energy was standardization.

\section{CONCLUSION}

In this paper, the management method of rural electricity load was proposed by deploying demand side management platform in the field of agricultural production. The transformation from traditional energy heating to power heating has been promoted in order to the enhancement of power proportion in rural areas and the expansion of power consumption. The application of smart grid in rural area optimizes crop growth conditions, lowers production costs, reduces manpower and improves efficiency. Thus it further promotes the economic development and agricultural production intelligent construction. The results of this paper laid a good foundation for the application of the smart grid in the rural area.

\section{REFERENCES}

[1] Hamidi, V.; Furong Li; Liangzhong Yao; Bazargan, M., "Domestic demand side management for increasing the value of wind," China International Conference on Electricity Distribution, 2008, pp. 17-10, 2008.

[2] Teansri, P.; Hongpeechar, B.; Intarajinda, R.; Bhasaputra, P.; Pattaraprakorn, W., "Multi-scenarios of effective demand side management in Navanakorn industrial promotion zone,” 2010 Proceedings of the International Conference on Energy and Sustainable Development: Issues and Strategies (ESD),. pp. 1-6, 2010.

[3] Kunold, I.; Kuller, M. ; Bauer, J.; Karaoglan, N. and C. P. Bean, “A system concept of an energy information system in flats using wireless technologies and smart metering devices," Intelligent Data Acquisition and Advanced Computing Systems (IDAACS), 2011 IEEE 6th International Conference on, 2011, pp. 812-816.

[4] Gudi, N.; Lingfeng Wang; Devabhaktuni, V.; Depuru, S.S.S.R., “A demand-side management simulation platform incorporating optimal management of distributed renewable resources," 2011 IEEE/PES of Power Systems Conference and Exposition (PSCE), pp. 1-7, 2011.

[5] Di Giorgio, A.; Pimpinella, L.; Quaresima, A.; Curti, S., “An event driven Smart Home Controller enabling cost effective use of electric energy and automated Demand Side Management," 2011 19th Mediterranean Conference on Control \& Automation (MED), pp. 358-364, 2011

[6] Logenthiran, T.; Srinivasan, D.; Tan Zong Shun, "Demand Side Management in Smart Grid Using Heuristic Optimization,” IEEE Transactions on Smart Grid, pp. 1244-1252, 2012. 